\title{
BANGLADESH IN THE ROAD TO ELIMINATE VIRAL HEPATITIS B
}

\author{
PERVIN M
}

The strategy of the World Health Organization (WHO) for elimination of viral hepatitis B and C was adopted in 2016. Bangladesh is a cosigner of the elimination program of WHO and preparing to eliminate the Hepatitis $\mathrm{B}$ virus (HBV) related morbidity and mortality in near future. The Global burden of chronic HBV is approximately 257 million and in $2013 \mathrm{HBV}$ related death was about $686000^{1}$. Bangladesh has an estimated prevalence of $5.4 \% \mathrm{HBV}$ infection shown in a study carried out in 2008 2 and $7.5 \%$ HBsAg sero-prevalence in another study and more than 10 million patients are chronically infected with HBV and Hepatitis C virus $(\mathrm{HCV})^{3}$. The morbidity and mortality from viral hepatitis is mostly due to acute fulminate hepatitis, cirrhosis and hepato-cellular carcinoma (HCC) the $6^{\text {th }}$ common cancer and $2^{\text {nd }}$ important cause of cancer related death globally ${ }^{3}$. More than 20,000 deaths occur annually in Bangladesh is due to HCC and different studies showed that $47-61 \%$ cause of $\mathrm{HCC}$ is due to HBV infection ${ }^{3}$. The disease burden is increasing in Bangladesh and a data from the department of Virology Dhaka Medical College from 2011 to 2015 showed the rate of HBsAg positivity was always above $20 \%{ }^{4}$. Therefore the initiative of WHO was appropriate and the response to this problem from Bangladesh is very urgent and well timely.

Viral Hepatitis is systemic disease caused by Hepatitis viruses (A,B,C,E and D) and spread through parenteral route, sexual route and from mother to child (B,C,D). Hepatitis A and E virus spread through fecal-oral route. Infection with HBV may produce acute hepatitis and chronic liver disease but majority produces asymptomatic infection and carrier state. The spectrum of disease is diverse and variable ranging from immuno-tolerance to carrier state and more severe chronic active hepatitis, cirrhosis and $\mathrm{HCC}^{5}$. It is mainly transmitted through sharing the needle of injection syringe, use of unsterile surgical, body piercing and dental instruments, infected blood and blood products, peri-natal transmission from mother to child and sexual route ${ }^{6}$. Its spread can be prevented by safe injection practices, surgical practices, treatment and vaccination of infected mother and baby during per-inatal period and practices of safe sex. In low endemic countries like America where injecting drug use and high risk sexual practice is the main route of transmission and the young adults are the predominant affected age group ${ }^{7}$. In Bangladesh both the practices are increasing and studies showed the predominant age group infected are young adults $4,8,9,10$. This condition warrants immediate action to prevent infection among these high risk groups.

HBV has different genotypes which could produce disease of different severity and respond to treatment differently. In Bangladesh, the infecting virus is mainly in the genotype $\mathrm{C}$ and $\mathrm{D}$ which respond poor to treatment ${ }^{11}$. It was also found that among inactive carrier state patients $26 \%$ had moderate necro-inflammatory changes, 17 had severe hepatic fibrosis and 10 patients had both the changes ${ }^{12}$. Another study showed in spite of low viral load and Alanine aminotransferase (ALT) level, a significant number of patients had severe hepatic fibrosis. ${ }^{13}$ Another study showed that HBeAg negative patients had more severe micro inflammation and fibrosis of liver ${ }^{14}$. These facts should be kept in mind while preparing prevention strategy. 
Treatment of HBV infection is available in Bangladesh and patients are enjoying ant-virals like Lamivudine, Adefovir, Entecavie and Tenofovir ${ }^{11}$. However the response to treatment is variable and sometimes relapses occur. It is also a reality that treatment is still expensive and is beyond the reach of many people of Bangladesh. On the other hand, HBV has effective and safe vaccine available which can prevent the transmission and ultimately the adverse outcome of the disease such as cirrhosis and HCC. Bangladesh is also producing vaccine by its own manufacturer. Considering these facts Bangladesh has started universal HBV vaccination program for the children since 2004 and achieved more than $90 \%$ coverage of HBV vaccine under 5 children ${ }^{15}$. In addition, Safe blood transfusion program and disposable needle syringe program was introduced in decades ago the result of which we have already found in reduction of prevalence in recent time ${ }^{16}$.

In recent years Bangladesh had expansion in treatment facilities and in infrastructure. Different Non Government Organizations (NGOs), support groups like Association for Study of Liver Diseases (ASLBD), Society of Hepatology and Virology are participating in diagnosis, treatment and awareness building programs for prevention of HBV infection. These combined effort had some impact in the reduction of HBV prevalence in last few years and the prevalence were reduced in general population ${ }^{16}$. This concerted effort of Government and other groups will create the basis of elimination of HBV infection by 2030 .

To achieve the national target of elimination still we have many difficulties which we need to overcome. People are unaware about the transmission routes, practicing unsafe surgery, needle prick, and dental procedures which will hamper the progress of elimination. Vaccination is unavailable for adults from the Government and people are also reluctant to receive vaccine even if they are in the risk group. There is still no designated program for control of viral hepatitis like other infectious diseases. Therefore, outside the cities there are no activities related to awareness and prevention of HBV. Bangladesh Government must consider prevention programs for high risk people like IDU and sex workers. To achieve the target, we need parallel programs like Malaria, Diarrhea, and Polio etc. to coordinate different support group's activities. So Government's health department should take multidisciplinary action programs in awareness building and make a national guideline for management and prevention viral hepatitis.

J Dhaka Med Coll. 2017; 26(2) :86-88

\section{References:}

1. WHO. Hepatitis B, Fact Sheet 2017. Accessed on : 26 March at $1.57 \mathrm{pm} \mathrm{http://www.who.int/}$ mediacentre/factsheets/fs204/en/

2. Al Mahtab M, Rahman S, Foster G, Khan M, Karim MF, Solaiman S, Afroz S. Epidemiology of hepatitis B virus in Bangladeshi general population. Hepatobiliary Pancreat Dis Int 2008 Dec;7(6):595600.

3. Al-Mahtab M. Epidemiology of Viral Hepatitis and Liver Diseases in Bangladesh. Euroasian J HepatoGastroenterol 2015;5(1):26-29.

4. Department of Virology. Dhaka Medical College. Departmental data from 2011-2016 for viral Hepatitis. 2018. (Personal communication).

5. Alavian SM, Fallahian F, Lankarani KB. The changing epidemiology of viral hepatitis B in Iran. J Gastrointestin Liver Dis. 2007; 16(4): 403-406 .

6. Chu CM, Liaw YF. Natural History of Hepatitis B Virus Infection. In: Liaw YF, Zoulim F (Eds.), Hepatitis B Virus in Human Diseases. 2016. Springer International Publishing, Switzerland, pp 217- 247.

7. Fattovich G. Natural history of hepatitis B. J Hepatol. 2003; 39(Suppl 1): 50-58.

8. Alam S, Azam G, Mustafa G, Alam M, Ahmad N. Past, Present, and Future of Hepatitis B and Fatty Liver in Bangladesh. Gastroenterol Hepatol. 2017; 6(3): 00197. DOI: 10.15406/ghoa.2017.06.00197

9. Mast EE, Weinbaum CM, Fiore AE, et al. A comprehensive immunization strategy to eliminate transmission of hepatitis B virus infection in the United States. Recommendations of the Advisory Committee on immunization practices (ACIP) Part II: immunization of adults. MMWR 2006; 55 (RR-16): $1-33$.

10. Shirin T, Ahmed T, Iqbal A, Islam M, Islam MN. Prevalence and risk factors of hepatitis B virus, hepatitis $\mathrm{C}$ virus, and human immunodeficiency virus infections among drug addicts in Bangladesh. J Health Popul Nutr. 2000;18(3):145-150.

11. Al Mahtab M. Elimination of Hepatitis Viruses: 
Bangladesh Scenario. Euroasian J HepatoGastroenterol 2017;7(1):40-42.

12. Al Mahtab M, Rahman S, Akbar SM, Kamal M, Khan SI. Clini-cal use of liver biopsy for the diagnosis and management of inactive and asymptomatic hepatitis B virus carriers in Bangladesh. J Med Virol 2010; 82(8):1350-1354.

13. Al Mahtab M, Akbar SMF, Rahman S, Kamal M, Khan MSI. Biochemical, virological, immunological and histopatho-logical features of 702 incidentally detected chronic hepatitis B virus carriers in Bangladesh. Digestion 2012;86(1):1-5.

14. Al Mahtab M, Rahman S, Khan M, Mamun AA, Kamal M. Pre-core/core Promoter mutant hepatitis B virus produces more severe histologic liver disease than wild type hepatitis B virus. Hungarian Med J 2007; 1(1):41-46.

15. Ahmad SM, Hossain MB, Monirujjaman M, Islam S, Huda MN, et al. Maternal zinc supplementation improves hepatitis B antibody responses in infants but decreases plasma zinc level. Eur J Nutr .2015; 55(5): 1823-1829.

16. GBD 2013 Mortality and Causes of Death Collaborators. Global, regional, and national age-sex specific all-cause and cause-specific mortality for 240 causes of death, 1990-2013: a systematic analysis for the Global Burden of Disease Study 2013. Lancet 2015; 385: 117-71. 